\title{
TRABALHO DOCENTE E SAÚDE DAS PROFESSORAS DE EDUCAÇÃO INFANTIL DE PELOTAS, RIO GRANDE DO SUL
}

\author{
THE TEACHING PROFESSION AND THE HEALTH OF THE CHILDHOOD EDUCATION TEACHERS IN \\ PELOTAS, RIO GRANDE DO SUL, BRAZIL
}

TRABAJO DOCENTE Y SALUD DE LAS MAESTRAS DE EDUCACIÓN INFANTIL DE PELOTAS, RIO GRANDE DO SUL, BRASIL

\author{
Jarbas Santos Vieira ${ }^{1}$ \\ Vanessa Bugs Gonçalves ${ }^{2}$ \\ Maria de Fátima Duarte Martins ${ }^{3}$
}

Resumo O objetivo deste artigo é discutir a relação entre processo de trabalho docente e a saúde de 196 professoras que atuavam em escolas municipais de educação infantil do município de Pelotas, Rio Grande do Sul, em 2011. Metodologicamente, a pesquisa se desenvolveu em duas etapas: uma quantitativa e outra qualitativa. Na dimensão quantitativa foi aplicado, sobre todo o corpo docente, o Job Content Questionnaire, cuja finalidade é investigar as rotinas ocupacionais do trabalho que são consideradas um risco à saúde dos trabalhadores. Na dimensão qualitativa, a coleta de dados se deu por meio de entrevistas semiestruturadas sobre as práticas educacionais das professoras em seu cotidiano de trabalho e o que as cerca. O eixo das entrevistas abordou o cotidiano de trabalho dessas docentes e suas percepções acerca da importância da professora de educação infantil. A análise mostrou que os discursos prevalentes reforçam a ideia do magistério como sacerdócio, naturalizando a ideia de doação e sacrifício como intrínsecas ao processo de trabalho docente.

Palavras-chave educação infantil; mal-estar docente; processo de trabalho docente.
Abstract The purpose of this article is to discuss the relationship between the teaching process and the health of 196 teachers working at municipal preschools in Pelotas, Rio Grande do Sul, Brazil, in 2011. Methodologically, the research was developed in two stages, a quantitative and a qualitative one. In the quantitative dimension, a Job Content Questionnaire was applied to the entire faculty, the purpose of which is to investigate the occupational routines of the work that are considered a risk to the workers' health. In the qualitative dimension, data collection was carried out through semi-structured interviews on the teachers' educational practices in their daily work and about what surrounds them. The axis of the interviews addressed the daily work of these teachers and their perceptions about the importance of the early childhood education teacher. The analysis showed that the prevailing discourses reinforce the idea of teaching as a priesthood, naturalizing the idea of giving and sacrifice as intrinsic to the teaching process.

Keywords childhood education; teaching uneasiness; teaching work process. 


\section{Introdução}

A rede pública municipal de Pelotas, no estado do Rio Grande do Sul, é um campo privilegiado para investigar questões sobre a relação entre o processo de trabalho docente e a saúde de professoras que atuam em escolas municipais de educação infantil (Emeis) da cidade, haja vista que o 'mal-estar docente' está entre as principais causas da solicitação de licenças de saúde pelas professoras da educação básica (Vieira et al., 2009, 2010). Tal fato acaba afastando grande número de docentes das salas de aula. Esses afastamentos contrariam a ideia de que o trabalho deveria proporcionar, além de oportunidades para o desenvolvimento de aptidões e de ampliação de conhecimentos pessoais - compensação econômica e satisfação emocional -, sentimento de bem-estar dentro e fora do local de trabalho.

O mal-estar docente é um termo utilizado para "descrever os efeitos permanentes de caráter negativo que afetam a personalidade do professor como resultado das condições psicológicas e sociais em que exerce a docência, devido à mudança social acelerada" (Esteve, 1999, p. 98).

Para melhor compreender como o mal-estar docente interfere no trabalho dos professores, Esteve (1999) distingue-o entre fatores primários e secundários. Os fatores primários exercem influência direta no trabalho de professores e professoras: recursos materiais e condições de trabalho; violência nas instituições escolares; esgotamento do docente diante da acumulação de exigências sobre o professor. Já os fatores secundários estão relacionados ao exercício docente e podem ser desencadeados por cinco fatores: a modificação no papel do professor e dos agentes tradicionais de socialização; a função docente no campo das contestações e das contradições; as modificações do apoio no contexto social; os objetivos do sistema de ensino; e o avanço do conhecimento e da mudança na imagem do professor (Esteve, 1999).

\section{Percurso metodológico}

Neste artigo 4 discute-se a relação entre processo de trabalho docente e a saúde das professoras que atuam em Emeis da cidade de Pelotas, Rio Grande do Sul, tendo como foco os resultados da pesquisa "A produção do mal-estar docente nas escolas municipais de educação infantil de Pelotas" (Jarbas et al. 2012).

Tomou-se como base os dados coletados pelo questionário Job Content Questionnaire (JCQ) e as entrevistas com professoras que atuam na educação infantil da rede pública municipal, visando explorar as dimensões quantitativas e qualitativas da relação entre trabalho docente e saúde das professoras que atuam nas Emeis.

O JCQ, utilizado na dimensão quantitativa, é um instrumento metodológico elaborado por Karasek (1985), cuja finalidade é investigar as rotinas 
ocupacionais do trabalho que são consideradas um risco à saúde dos trabalhadores. Esse instrumento é composto por 49 questões (versão recomendada) que abordam controle e demanda do trabalhador, suporte social dos cargos de chefia e dos colegas de trabalho, assim como demandas físicas e insegurança no emprego. O JCQ foi aplicado sobre todo o corpo docente - 196 professoras - que estava em sala de aula nas 27 escolas de educação infantil da cidade de Pelotas nos meses de maio e junho de 2011.

Do universo de 196 respondentes, 195 são mulheres. Em relação ao estado civil, $56,6 \%$ são casadas, $32,7 \%$ solteiras e $6,6 \%$ separadas. A idade do grupo varia entre 22 e 61 anos, com média de idade de 38 anos. Quanto ao nível de escolaridade, 27,6\% possuem nível superior completo e $23 \%$ superior incompleto. O tempo médio na profissão é de nove anos. A carga horária de todas as professoras é de quarenta horas semanais ou mais.

As entrevistas semiestruturadas analisadas para a construção deste artigo, realizadas na escola da professora e em seu horário de trabalho, somaram 14. Para o estudo, optou-se por entrevistar uma docente por escola, o que totalizava 27 entrevistas na etapa qualitativa. No entanto, por saturação dos dados, foram entrevistadas 14 professoras das 27 Emeis.

O projeto foi aprovado pelo Comitê de Ética em Pesquisa Envolvendo Seres Humanos da Universidade Federal de Pelotas (UFPel), e as recomendações da resolução n. 196/96 foram criteriosamente seguidas.

\section{Resultados e discussão}

Além dos resultados obtidos pelo instrumento metodológico de Karasek (1979; 1985), na dimensão qualitativa foi problematizada a especificidade do processo de trabalho docente, explorando o cotidiano laboral das professoras, assim como os sentidos e os significados que circulam em seus discursos sobre educação infantil e sua atuação nesse nível de escolaridade.

A versão utilizada do JCQ contempla as duas dimensões psicossociais do trabalho: as demandas psicológicas advindas do trabalho e o controle que a professora tem sobre essas demandas. A 'demanda psicológica' diz respeito às exigências psicológicas que as professoras enfrentam na realização de seu trabalho. Envolve pressão do tempo, nível de concentração requerido, interrupção das tarefas e necessidade de esperar pelas atividades realizadas pelos colegas. O questionário também avalia o suporte social proveniente da direção e dos colegas de trabalho e, por fim, a demanda física e a insegurança no emprego.

$\mathrm{O}$ 'controle no trabalho' refere-se ao uso de habilidades - o grau pelo qual o trabalho envolve aprendizagem de coisas novas. O desenvolvimento de habilidades especiais individuais também envolve autoridade de decisão, que abarca a habi- 
lidade individual para a tomada de decisão sobre o próprio trabalho, a influência do grupo de trabalho e a influência na política de gestão (Araújo, Graça e Araújo, 2003).

Os dados coletados pelo JCQ contribuíram para a composição de uma tabela que evidencia as relações de demanda e controle dessas profissionais no desenvolvimento de seu trabalho (Tabela 1):

Tabela 1

Distribuição das características psicossociais do trabalho, segundo as professoras da rede municipal de educação infantil de Pelotas (2011)

\begin{tabular}{|c|c|c|}
\hline Indicadores de uso de habilidades & $\mathrm{n}$ & $\%$ \\
\hline \multicolumn{3}{|l|}{ Controle sobre o próprio trabalho $(n=196)$} \\
\hline Trabalho envolve aprendizagem de coisas novas & 194 & 99,0 \\
\hline Trabalho repetitivo & 141 & 71,9 \\
\hline Requer criatividade & 195 & 99,5 \\
\hline Exigência de alto nível de habilidade & 175 & 89,2 \\
\hline Possibilita fazer tarefas diferentes & 176 & 89,8 \\
\hline Possibilita desenvolver minhas habilidades especiais & 177 & 90,0 \\
\hline \multicolumn{3}{|l|}{ Indicadores de autoridade decisória $(n=196)$} \\
\hline Permite tomar decisão por conta própria & 130 & 66,3 \\
\hline Tem pouca liberdade para decidir como fazer o próprio trabalho & 36 & 18,4 \\
\hline O que você diz sobre seu trabalho é considerado & 160 & 81,6 \\
\hline 10 a 20 pessoas trabalham em sua escola & 96 & 49,0 \\
\hline Eu tenho influência significativa sobre as decisões em minha escola & 133 & 67,8 \\
\hline Minha escola toma decisões democraticamente & 148 & 75,5 \\
\hline Possibilidade de que minhas ideias sejam consideradas em relação às políticas da escola & 84 & 42,8 \\
\hline Não supervisiono outras pessoas & 178 & 90,8 \\
\hline Associada ao sindicato ou associação de professores & 76 & 38,8 \\
\hline Eu tenho influência sobre as políticas do sindicato ou associação de professores & 51 & 26,0 \\
\hline \multicolumn{3}{|l|}{ Demandas psicológicas $(n=196)$} \\
\hline Ritmo de trabalho acelerado & 71 & 36,3 \\
\hline Trabalhar muito & 177 & 90,3 \\
\hline Volume excessivo de trabalho & 70 & 35,7 \\
\hline O tempo é insuficiente para realização das tarefas & 128 & 65,3 \\
\hline Trabalho com demandas conflitantes feitas por outros & 134 & 68,4 \\
\hline Intensa concentração na tarefa & 132 & 67,4 \\
\hline Tarefas são interrompidas antes de concluí-las & 141 & 72,0 \\
\hline Trabalho de modo frenético & 74 & 37,8 \\
\hline Esperar pelo trabalho dos outros torna meu trabalho mais lento & 144 & 73,4 \\
\hline
\end{tabular}

Fonte: Banco de dados da pesquisa (Vieira et al., 2012). 
Como pode ser visto na Tabela 1, existe uma compreensão de que o trabalho com crianças pequenas envolve constantes aprendizagens. Essa positividade, encontrada nas descrições de habilidades do JCQ, também é afirmada em relação ao grau de autoridade que as docentes acreditam possuir em relação às decisões em sala de aula e no espaço da escola.

Os dados apresentam profissionais que acreditam ter alto nível de especialização e grande autonomia laboral, o que poderia tornar-se um fator de satisfação e, consequentemente, de proteção a problemas relacionados ao 'mal-estar docente' ou a qualquer outra doença relacionada ao processo de trabalho. Todavia, se prestarmos atenção às demandas psicológicas (Tabela 1), encontramos professoras que trabalham intensivamente e com tempo insuficiente para a realização das tarefas que lhes são exigidas. É um trabalho que envolve, cotidianamente, demandas conflitantes, intensa concentração nas tarefas e constantes interrupções por problemas existentes dentro da própria organização escolar.

As respostas das professoras ao JCQ foram distribuídas de acordo com o modelo demanda/controle. Este modelo distingue quatro tipos básicos de experiências no trabalho, gerados pela interação dos níveis 'alto' e 'baixo' da demanda psicológica e 'alto' e ' baixo' do controle, em que 'alta exigência do trabalho' é caracterizada como alta demanda e baixo controle; 'trabalho ativo', por alta demanda e alto controle; 'trabalho passivo', por baixa demanda e baixo controle; e 'baixa exigência', por baixa demanda e alto controle.

Na distribuição das respostas das professoras segundo o modelo demanda/controle, no diagrama de quatro quadrantes, obtém-se a característica das hipóteses preditas pelo próprio modelo, referentes ao maior risco de adoecimento ('diagonal $\mathrm{A}^{\prime}$ ), assim como a hipótese de existência de motivação para o desenvolvimento de novos padrões de comportamento ('diagonal B') (Figura 1). 
Modelo demanda-controle de professoras de educação infantil de Pelotas, Rio Grande do Sul

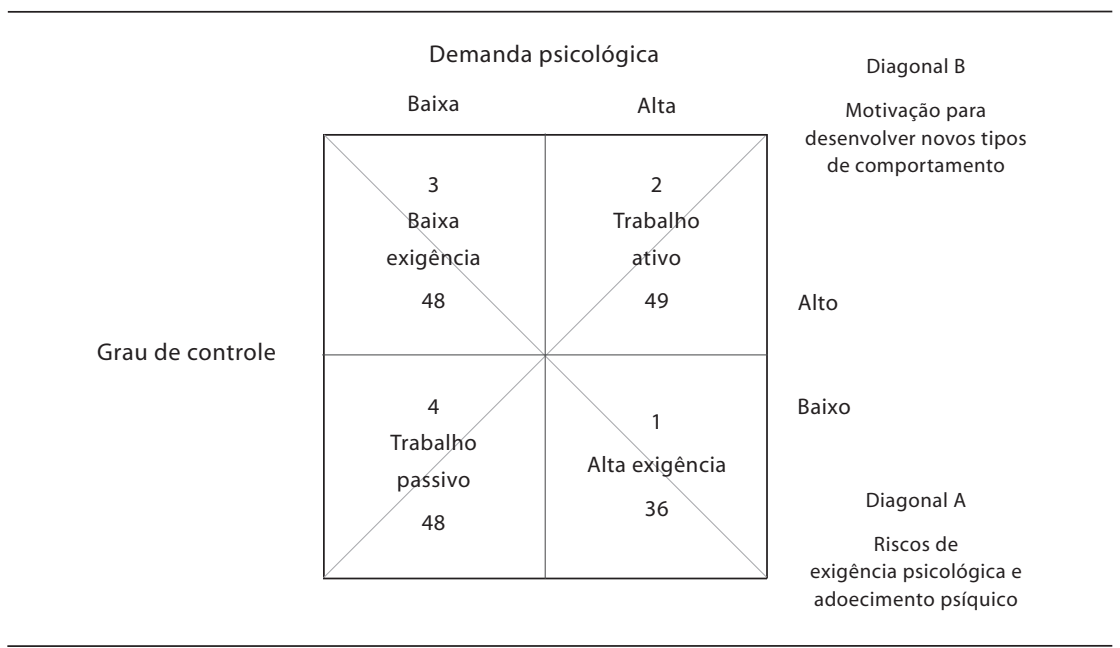

Fonte: Dados dos autores em modelo de Karasek e Theorell (1990).

Como pode ser depreendido da Figura 1, 49 professoras apresentaram alta demanda psicológica e alto grau de controle sobre seu trabalho; 48 apresentaram baixa demanda psicológica e alto grau de controle, considerado como o grupo de referência, isto é, professoras que não estão expostas a doenças. Outras 48 professoras encontram-se também no quadrante intermediário. Não obstante, 36 encontram-se no grupo de risco referido a um trabalho em que é exigida alta demanda psicológica e há pouco controle sobre o seu trabalho, o que as coloca em risco de adoecimento.

Nos estudos apresentados por Karasek (1985), é possível observar que as profissões referentes ao cuidado e ao atendimento ao público constituem o quadrante relacionado à alta exigência e integram a 'diagonal A', que aponta para riscos de distúrbios de ordem psicológica e de doenças físicas.

No caso das professoras das Emeis, a existência de um número significativo de profissionais no quadrante inferior direito (trabalho passivo), o qual é apontado pelo modelo como fator de declínio na atividade global do indivíduo, provoca uma redução da capacidade de produzir soluções para as atividades e problemas enfrentados (Araújo e Karasek, 2008).

Corroborando os dados apresentados, as entrevistas semiestruturadas apresentam algumas especificidades no que diz respeito ao processo de trabalho dessas professoras, conforme relata a entrevistada acerca de suas percepções do trabalho na educação infantil:

A jornada é cansativa, o horário poderia ser reduzido e poderia ser duas turmas se não tivesse o horário do sono na educação infantil. Os maiores não teriam essa 
necessidade para dormir (...) e se tivesse um espaço com outras atividades, ter contato com o professor de música, que faz falta na EI [educação infantil], professor de artes, uma área específica que pudesse trabalhar outras habilidades (professora 2).

Todavia, interessa neste momento explorar a produção do 'mal-estar docente' dentro do processo de trabalho dessas professoras. E os dados referidos ao suporte social podem favorecer a análise.

Segundo os dados coletados pelo JCQ, existe um suporte social por parte da direção e das colegas de trabalho, indicando um ambiente favorável ao trabalho em grupo, conforme pode ser visto na Tabela 2 :

Tabela 2

Distribuição sobre o suporte social, segundo as professoras da rede municipal de educação infantil de Pelotas (2011)

\begin{tabular}{|c|c|c|}
\hline Indicadores de uso de habilidades & n & $\%$ \\
\hline \multicolumn{3}{|l|}{ Suporte social $(n=196)$} \\
\hline Minha diretora preocupa-se com o bem-estar de suas professoras e funcionárias & 168 & 85,7 \\
\hline Minha diretora presta atenção às coisas que eu digo & 169 & 86,3 \\
\hline Eu estou exposta a conflitos ou hostilidade por parte da diretora & 43 & 21,9 \\
\hline Minha diretora me ajuda na realização de meu trabalho & 144 & 73,5 \\
\hline Minha diretora é bem-sucedida em promover o trabalho em equipe & 153 & 78,1 \\
\hline \multicolumn{3}{|l|}{ Apoio recebido pelos colegas de trabalho $(n=196)$} \\
\hline As pessoas com quem trabalho são competentes na realização de suas atividades & 175 & 89,3 \\
\hline As pessoas com quem trabalho se interessam pelo que acontece comigo & 173 & 88,3 \\
\hline Estou exposta a conflitos ou hostilidades por parte das pessoas com quem eu trabalho & 89 & 45,5 \\
\hline As pessoas com quem trabalho são amigáveis & 179 & 91,3 \\
\hline As pessoas com quem trabalho encorajam, umas às outras, a trabalharem juntas & 154 & 78,6 \\
\hline As pessoas com quem trabalho são colaborativas na realização das atividades & 173 & 88,3 \\
\hline
\end{tabular}

Fonte: Banco de dados da pesquisa (Vieira et al., 2012).

Mas como entender esse suporte social quando - nos dados relacionados ao controle sobre seu processo de trabalho - o que aparece é uma professora que precisa resolver problemas de ordem pedagógica de forma individualizada?

As duas questões aparentemente paradoxais até aqui apresentadas 1) a ideia de uma profissional especializada e criativa, com autonomia decisória, mas que trabalha sob demandas conflitantes e sob intensa concentração; 2) suporte social e ambiente de trabalho satisfatório, embora suas decisões pedagógicas sejam individualizadas - indicaram a necessidade de um 
mergulho qualitativo no universo dessas professoras, pois os dados coletados pelo JCQ, mesmo indicando uma categoria potencialmente em risco de adoecimento psicológico, indicam também que essas docentes ainda mantêm muitas prerrogativas em seu processo de trabalho.

Entretanto, essas prerrogativas não aliviam questões potencialmente causadoras de problemas de saúde, como é o caso das demandas físicas do trabalho (Tabela 3).

Tabela 3

Distribuição das demandas físicas advindas do trabalho, segundo as professoras da rede municipal de educação infantil de Pelotas (2011)

\begin{tabular}{lcc}
\hline Demanda psicológica & $\mathbf{n}$ & $\%$ \\
\hline & & \\
Meu trabalho exige muito esforço físico & 131 & 66,9 \\
Frequentemente sou solicitada a mover ou levantar pesos em meu trabalho & 107 & 54,6 \\
Meu trabalho exige atividade física rápida e contínua & 114 & 58,1 \\
Manter o corpo em posição incômoda & 104 & 53,0 \\
Cabeça e braços em posições físicas incômodas & 87 & 44,4 \\
\end{tabular}

Fonte: Banco de dados da pesquisa (Vieira et al., 2012).

Os dados do instrumento são efetivamente confirmados pelos relatos das professoras entrevistadas:

Estou na turma do maternal A, que são crianças de dois a três anos, e é um processo bem difícil, porque eles estão saindo do berçário, onde usavam fralda, tomavam mamadeira (...) muitos deles estavam há dois anos lá no berçário, agora eles estão trocando, aprendendo a usar o vaso, e ainda é meio complicado para eles. É um processo físico bem cansativo: tu tens que carregar, tem que levantar no colo, todo aquele procedimento. Se escapar e vazar na roupinha, tem que levar lá no berçário, trocar, todo o processo novamente. Não é muito fácil, fisicamente é bem cansativo, bem estressante (professora 3).

Esse desgaste físico pode ser um fator que compromete o trabalho docente, pois sua jornada é intensificada, com pouco ou nenhum tempo de descanso durante a jornada de trabalho:

Não se consegue ir a médico. Não se consegue grande coisa. Depois que tu entras para cá [educação infantil], mal atendes um telefone. Se tiverem chorando, tu dizes "daqui a pouco eu te ligo". Tu acabas te esquecendo. Aqui a gente se desliga de 
tudo; tu não vês nem jornal. Caiu um prédio, uma coisa na rua e tu não ficas nem sabendo. Ficas sabendo depois que tu sais daqui de dentro (professora 4).

Já os aspectos relacionados à insegurança no trabalho não preocupam as professoras, embora elas percebam que suas qualificações se desgastarão em curto prazo. A carreira docente na educação infantil não é vista como propícia a promoções, uma vez que a função desempenhada e o cargo ocupado são muito específicos. Talvez seja essa especificidade que faz as professoras se enxergarem como trabalhadoras especializadas (Tabela 4).

Tabela 4

\begin{tabular}{lcc}
$\begin{array}{l}\text { Distribuição da insegurança no trabalho, segundo as professoras da rede municipal de } \\
\text { educaça infantil de Pelotas (2011) }\end{array}$ & $\mathbf{n}$ & $\%$ \\
\hline Segurança no trabalho & 168 & 85,7 \\
Seu trabalho é regular e estável & 184 & 93,9 \\
Minha estabilidade no emprego é boa & 187 & 95,4 \\
Esteve empregada no ano passado & 2 & 1,0 \\
Possibilidade de perda do emprego nos próximos 2 anos & 99 & 50,5 \\
Possibilidades de crescimento na carreira ou promoções & 156 & 79,6 \\
Minhas qualificações continuarão válidas em 5 anos & &
\end{tabular}

Fonte: Banco de dados da pesquisa (Vieira et al., 2012).

Deve-se também levar em consideração que a população da pesquisa tem características que a distinguem de outras categorias, assim como de categorias semelhantes de outras regiões. Mesmo assim, é possível avançar algumas ideias para entender por que essas professoras, dentre todas as outras docentes que atuam na rede pública municipal, apresentam mais problemas de saúde, segundo constatado na pesquisa "Constituição das doenças da docência (Docenças) (2007-2009)".

Corroborando os resultados dessa pesquisa, também foram encontrados fatores que contribuem para o adoecimento das professoras, em especial as condições de trabalho e o tratamento que o poder público dispensa às Emeis. Como exemplo privilegiado desse tratamento, houve o aumento do número de crianças por professora no ano de 2011. O então secretário municipal de Educação, alegando haver espaço físico, mas desconsiderando a capacidade de trabalho e o mobiliário das salas, aumentou o número de crianças em cada sala de aula.

Outro exemplo para demonstrar o descaso do poder público em relação às Emeis pode ser o depoimento a seguir, em que a entrevistada relata a demora e a qualidade dos materiais disponibilizados para as escolas: 
(...) mas de material, nenhum apoio. Nada! Em setembro, outubro, vem algum material pra gente, mas é um horror, e o que vem é assim: giz que não pinta, cola que não cola, é uma [cola] líquida que não cola, muita coisa a gente tem que estar fazendo festa, rifa, essas coisas para poder arrecadar dinheiro (professora 4).

Esse excerto confirma o descaso do poder público dispensado às Emeis, uma vez que os materiais dispostos às professoras somente são distribuídos quando já se iniciaram as aulas. Tal problemática é enfrentada pelas professoras de modo que as próprias compram os materiais para que as crianças não fiquem sem o que elas julgam ser necessário para as aulas, conforme relata a entrevistada:

A gente comprou lápis de cor e dividiu três caixinhas para cada sala de aula. Eu comprei do meu dinheiro, porque a gente começou o ano letivo e essas crianças não tinham lápis de cor para pintar, porque gasta (...) o material que vem já não é de qualidade, então o lápis de cor, a criança tá sempre apontando, e aquele grafite tá quebrando, e eles pintam muito, eles gastam o lápis (professora 6).

A essa dimensão político-estrutural soma-se outra, de caráter simbólico, mas não menos real que aquela: trata-se de discursos de caráter idealista $\mathrm{e}$ prescritivo sobre o significado do trabalho docente e da própria educação. Discursos proferidos tanto pelas professoras quanto pela Secretaria Municipal de Educação, que acabam normalizando a ideia do magistério como sacrifício - naturalizado como um(o) elemento constituinte da ideia de profissão docente, pelo menos com crianças pequenas.

Não é possível ignorar que o papel do professorado mudou sob a pressão das transformações do contexto social, no qual elas e eles exercem a sua profissão; mas igualmente modificaram-se as expectativas, o apoio e o julgamento desse contexto social sobre as educadoras e os educadores (Esteve, 1999; Hypolito, 1997; Sacristán, 2008). Isso tem aumentado o 'mal-estar docente' das professoras de educação infantil, que vêm experimentando rápidas modificações de exigências e novas responsabilidades - muito pela diminuição do papel educador da família -, além da modificação do seu papel docente diante das novas tecnologias (competição com TV, internet etc.) e da falta de preparação para esse novo papel.

No caso das docentes da educação infantil, os resultados obtidos permitem questionar o trabalho atual nas Emeis como valor para a saúde dessas professoras. Os dados indicam que essa categoria, em termos de saúde, parece andar na contramão da ideia de que o trabalho é um elemento fundamental para fazer com que as pessoas se sintam úteis e importantes - um sentimento sadio de pertencer e de contribuir para a sociedade, sentimento que deveria ser fundamental num trabalho como o da educação. Sua ausên- 
cia se constitui em um dos fatores do 'mal-estar docente' que, combinados com questões de ordem individual, organizacional e social, influenciam a saúde, o desempenho e a satisfação das professoras.

Como escrito em outro momento (Vieira et al., 2009, 2010), nas atuais condições de trabalho da maioria de nossas escolas públicas, a docência encontra-se em constante risco de promover o adoecimento do professorado, em vez de contribuir para produzir alguma espécie de compensação, seja econômica, seja emocional. Essa realidade torna-se ainda mais complexa quando se fala da educação básica e, em especial, das professoras das Emeis, pois são elas as mais destacadas pela sociedade para lidar, como linha de frente, com a dura realidade da miséria, da violência e da exclusão, como bem exemplifica a seguinte professora:

(...) a questão da aluna em si sempre foi uma questão que mexeu muito comigo. Então, ter uma criança, por exemplo, que passa fome, tu podes resolver o problema em um determinado instante, mas tu sabes que daqui a pouco tu não vais poder resolver mais. Essa criança precisa da escola para alimentação, mas e depois que sai daqui da escola? O que vai acontecer? Eu não posso estar lá, e se eu pudesse estar lá, não ia poder estar na casa do outro... (professora 1).

A esse contexto social somam-se a falta de apoio por parte dos órgãos coordenadores da educação, o crescimento de cobranças por parte da sociedade e a hipertrofia de funções, tornando a tarefa de educar uma tarefa de risco para a saúde dessas pessoas.

Diante de tantas dificuldades, não é de estranhar que as professoras coloquem em jogo diversos mecanismos de defesa para preservar sua integridade, como são os esquemas de inibição da rotina ou de absenteísmo trabalhista. Nos discursos delas, o trabalho em condições desfavoráveis tornou-se uma norma - uma normalidade - da profissão de educadora em escolas públicas, naturalizando o sentimento de que ser professora é sacrificar-se pessoalmente pelo bom andamento das relações educativas e dos múltiplos significados que possam ter para cada uma das docentes.

O absenteísmo é um dos aspectos decorrentes do mal-estar docente e ocorre comumente no cotidiano das escolas. Assim, não é rara, como nossos dados indicam, a solicitação de afastamentos devido ao sentimento de mal-estar sofrido pelas professoras. Todavia, não podemos ignorar que, mesmo sob pressão, o presenteísmo também se faz rotina nas Emeis, na medida em que professoras permanecem no âmbito escolar mesmo em situação de adoecimento, mantendo "suas atividades docentes para se sentirem úteis na sua missão de educar" (Paschoalino, 2009, p. 66).

$\mathrm{Na}$ ótica do presenteísmo, as professoras continuam desenvolvendo seu trabalho mesmo doentes, comprometendo a qualidade da educação e 
potencializando o agravamento de problemas físicos e psicológicos, conforme pode ser visto na fala de outra professora:

Eu tenho até atestado médico que eu não coloquei justamente para, aquele ano, eu continuar no berçário. No ano seguinte, também continuei... só que aí, ano passado, eu disse: "Bom, não tem mais, não tem mais condições" (professora 1).

Nas entrevistas analisadas, o presenteísmo muitas vezes é justificado pelas docentes por compreenderem sua profissão como vocação, uma missão quase sagrada, mais do que como uma profissão. A professora se constitui profissionalmente dentro de um ethos pastoral, cuja missão é a de salvamento das crianças.

As políticas educacionais exploram essa dimensão pastoral com rara destreza (Eslabão, 2011), construindo cenários que favorecem críticas à qualidade do trabalho das professoras, como é o caso da publicização de resultados negativos que podem ocorrer nas escolas. Um mau desempenho pedagógico, um fato negativo nas relações sociais educativas - entre professoras e crianças, professoras e famílias, professoras e secretaria-, é imediatamente relacionado à incompetência profissional que, por sua vez, é relacionada à falta de compromisso e de dedicação das docentes ou da escola. Essa combinação de profissão e sacerdócio vem deslegitimando as professoras como profissionais, criando mecanismos de interferência sobre o processo de trabalho docente, cada vez mais alinhado com aquilo que está prescrito nos documentos oficiais - da política municipal e da política curricular -, independentemente das realidades encontradas nas escolas.

O conjunto dessas questões tem levado a categoria a uma constante busca de atualização, em forma de cursos, treinamentos, oficinas, palestras etc., cujos efeitos estão muito mais próximos de um manual de autoajuda do que de uma formação intelectual que se converta em melhorias para a educação. Os cursos promovidos na rede pública de Pelotas, pelo menos nos últimos oito anos, são um exemplo dessas totalizações e imposições de modelos que, somados ao viés político conservador da atual administração, estabelecem controles mais rígidos sobre as professoras.

A combinação das dimensões político-estrutural e simbólica tem constituído um processo marcado pela intensividade e extensividade do processo de trabalho dessas professoras. Percebe-se nas Emeis que as possibilidades de porosidade são mínimas, pois o grau de atenção nas tarefas com crianças pequenas torna o cotidiano das professoras um exercício constante de vigilância.

Essas docentes têm uma jornada de trabalho de oito horas ou mais, com menos de uma hora para o almoço, às vezes nem isso, em razão de questões ligadas à adaptação das crianças e outras. Não são poucas as professoras que dizem ficar além do horário de trabalho esperando os pais ou responsáveis 
pelas crianças. Todavia, a jornada de trabalho não acaba quando a professora sai da escola. Em casa há também outra jornada de trabalho, que se confunde com os compromissos profissionais, como destaca outra professora:

(...) em casa [estou] pensando nas coisas da escola, mas não estou pensando parada, pensando em duas, três coisas. Acho que isso, sim, esgota. Tem coisa para fazer e ainda tá pensando em coisas lá da escola. Na verdade, na escola, tá pensando no que tem que fazer em casa também... Eu acho que a sobrecarga da gente é que esgota bastante. Recebo pouco pra trabalhar, recebo nada pra fazer a outra parte. Acho que isso aí enlouquece a cabeça da gente... A obrigação em casa é exclusivamente da gente [da mulher] (...) e chega uma hora que eu nem cobro mais ajuda [dos familiares] (professora 7).

\section{Considerações finais}

O volume de trabalho e a precariedade das condições existentes em muitas Emeis, a diversidade e a complexidade das questões presentes em sala de aula e, ainda, uma expectativa social de excelência podem estar na origem de queixas e de adoecimento da categoria. De toda forma, as professoras da educação infantil talvez sejam aquelas docentes cuja jornada de trabalho seja a mais extensa e a que mais esteja sendo intensificada. A isso se acrescenta o fato de serem as mulheres que historicamente têm uma jornada não remunerada de trabalho, em casa, com a família. ${ }^{5}$

Ademais, a professora carrega o estigma de ser a profissional da doação e se culpa por não alcançar os resultados almejados por ela e pela sociedade, pois atribui a si uma expectativa social incompatível com a realidade encontrada nas escolas (Paschoalino, 2009).

Nossa pesquisa indica que, em conjunto, existe uma estreita relação entre o atual processo de trabalho das professoras de educação infantil e seus problemas de saúde, contribuindo para o adoecimento individual - o que explica o número de professoras em risco de adoecimento segundo o modelo demanda-controle. São muitos os conflitos que fazem parte do dia a dia de professoras das Emeis, que se deparam com várias funções efetivamente desempenhadas e não estariam circunscritas na ótica da educação institucionalizada.

A complexidade do trabalho docente e a gama de atribuições impostas ao professorado permitem que uma série de discursos interfiram no trabalho docente. Nessa trama, as docentes podem considerar serem suas as responsabilidades e as mazelas encontradas cotidianamente nas escolas, e ao não alcançarem o objetivo esperado, sofrem por fracassarem. Ao não compartilharem as responsabilidades e os fracassos, o professor esgota, silencia e adoece por creditar a si a causa do não aprendizado, da violência, da pobreza... 
As professoras que permanecem nas Emeis por opção e buscam incessantemente a valorização profissional e social persistem na luta, apesar de numerosas dificuldades. O menor prestígio social que possuem por trabalharem em instituições ainda consideradas assistencialistas por muitos tem instigado algumas delas para o caminho da superação. Entretanto, ao mesmo tempo que se percebe o compromisso com o cuidado e a educação de crianças pequenas, elas também estão sujeitas à acomodação e a momentos de desânimo causados pela desvalorização salarial e pelas condições precárias de trabalho, talvez potencializando o próprio adoecimento de muitas delas.

São essas questões que ajudam a pensar a relação entre o processo de trabalho dessas professoras e sua saúde (ou seu adoecimento), abrindo a possibilidade de contribuição com a qualidade da educação e de suas profissionais nesse nível de escolaridade.

\section{Colaboradores}

Jarbas Santos Vieira foi responsável pela escrita e análise das entrevistas, visando ao estudo quantitativo e qualitativo deste estudo. Vanessa Bugs Gonçalves participou da escrita e análise das entrevistas das professoras (etapa qualitativa). Maria de Fátima Duarte Martins também colaborou na escrita, análise quantitativa e qualitativa, principalmente no que se refere aos aspectos psicossociais do trabalho.

\section{Nota do editor}

A despeito de o universo da pesquisa ter contado com um docente do sexo masculino - o que exigiria, seguindo as normas de revisão da revista e o uso comum pelos falantes de português, o emprego do gênero gramatical neutro as autoras e o autor optaram por empregar o gênero feminino ('professoras'), no sentido de registrar a maioria numérica do sexo feminino entre os docentes pesquisados. A Trabalho, Educação e Saúde, por reconhecer a dimensão ideológica da língua e identificar a relevância da tematização dos conflitos sociais de gênero - sendo o gênero inclusive já tratado em artigos publicados pelo periódico - acatou a decisão. Contudo, observamos que a revista, 
considerando a língua como instrumento intrinsecamente comunicativo e coletivo de vasto escopo, mantém, como referência, os usos socialmente comuns dos gêneros gramaticais, cujo desafio de recriação exige longos prazos e mobilizações coletivas amplas. Em função de todos os aspectos expostos, a editoria considerou pertinente o registro desta nota, com assentimento das autoras e do autor.

Resumen Este artículo tiene como objetivo discutir la relación entre el proceso de trabajo docente y la salud de 196 maestras que actuaban en escuelas municipales de educación infantil de Pelotas, Rio Grande do Sul, Brasil, en 2011. Metodológicamente, la investigación se desarrolló en dos etapas: una cuantitativa y otra cualitativa. En la dimensión cuantitativa, fue aplicado, en todo el cuerpo docente, el Job Content Questionnaire, cuya finalidad es investigar las rutinas ocupacionales del trabajo que son consideradas un riesgo para la salud de los trabajadores. En la dimensión cualitativa, la recolección de datos se realizó a través de entrevistas semiestructuradas sobre las prácticas educacionales de las maestras en su cotidiano laboral y su alrededor. El eje de las entrevistas abordó el cotidiano laboral de estas docentes y sus percepciones acerca de la importancia de la maestra de educación infantil. El análisis demostró que los discursos prevalentes refuerzan la idea del magisterio como sacerdocio, tomando con naturalidad la donación y el sacrificio como intrínsecos al proceso de trabajo docente.

Palabras clave educación infantil; malestar docente; proceso de trabajo docente.

\section{Notas}

1 Universidade Federal de Pelotas, Departamento de Fundamentos da Educação, Programa de Pós-Graduação em Educação, Pelotas, Rio Grande do Sul, Brasil.

<jarbas.vieira@gmail.com>

Correspondência: Rua Alberto Rosa, 154, Centro, CEP 96010-770, Pelotas, Rio Grande do Sul, Brasil.

2 Universidade Federal de Pelotas, Pelotas, Rio Grande do Sul, Brasil.

<nessabugs@gmail.com>

3 Universidade Federal de Pelotas, Departamento de Fundamentos da Educação, Programa de Pós-Graduação em Ensino de Ciências e Matemática, Pelotas, Rio Grande do Sul, Brasil.

<duartemartinsneia@gmail.com>

4 Este artigo foi extraído dos resultados de pesquisa financiada pelo Conselho Nacional de Desenvolvimento Científico e Tecnológico (CNPQ), no período 2010-2012, e desenvolvida nas escolas municipais de educação infantil (Emeis) da rede pública da cidade de Pelotas, Rio Grande do Sul. 
5 Em 1989 realizou-se o primeiro concurso público em Pelotas para prover o cargo de professora para a pré-escola, com exigência de formação mínima do curso de magistério. Venzke (2004, p. 54) relata que "algumas professoras nomeadas foram atuar em turmas de pré-escola nas creches municipais e outras nas escolas da rede municipal de ensino, conforme sua opção". Foi priorizada a pré-escola e a sua função pedagógica, o que não foi observado para as turmas de creches (crianças de 0 a 3 anos), onde, para trabalhar, bastava, de preferência, 'gostar de crianças e ser mulher'.

\section{Referências}

ARAÚJO, Tânia M.; GRAÇA, Cláudia C.; ARAÚJO, Edna. Estresse ocupacional e saúde: contribuições do modelo demanda-controle. Ciência \& Saúde Coletiva, Rio de Janeiro, v. 8, n. 4, 2003, p. 991-1.003.

ARAÚJO, Tânia M.; KARASEK, Robert. Validity and reliability of the Job Content Questionnaire in formal and informal jobs in Brazil. Scandinavian Journal of Work, Environment \& Health, Helsinki, supl. 6, p. 52-59, 2008.

ESLABÃO, Leomar C. Proeja: um dispositivo da governamentalidade produzindo posições de sujeito. Tese (Doutorado em Educação) - Universidade Federal de Pelotas, Pelotas, 2011.

ESTEVE, José S. O mal-estar docente. Bauru: Edusc, 1999.

KARASEK, Robert. Job demand, job decision latitude, and mental strain: implications for job redesign. Administrative Science Quarterly, Ithaca, n. 24, p. 285-308, 1979.

KARASEK, Robert. Job Content Questionnaire user's guide. Lowell: University of Massachusetts, 1985.

KARASEK, Robert; THEÖRELL, Thores. Health work: stress, productivity and the reconstruction of working life. Nova York: Basic Books, 1990
HYPOLITO, Álvaro M. Trabalho docente, classe social e relações de gênero. Campinas: Papirus, 1997.

PASCHOALINO, Jussara B. Q. O professor desencantado: matizes do trabalho docente. Belo Horizonte: Armazém de Ideias, 2009.

SACRISTÁN, José Gimeno. ¿De dónde viene la crisis de la profesión docente? Cadernos de Educação, Pelotas, n. 30, p. 78-88, jan.-jun. 2008

VENZKE, Lourdes H. M. Professoras das escolas municipais de educação infantil de Pelotas: identidades em construção. Dissertação (Mestrado em Educação) - Universidade Federal de Pelotas, Pelotas, 2004.

VIEIRA, Jarbas S. et al. Constituição das doenças da docência (Docença). Relatório de pesquisa. Brasília, Pelotas: CNPq; UFPel, 2009.

VIEIRA, Jarbas S. et al. Constituição das doenças da docência. Cadernos de Educação, Pelotas, n. 37, p. 303-324, set.-dez. 2010.

VIEIRA, Jarbas S. et al. Pesquisa "A produção do mal-estar docente em professoras de educação infantil": banco de dados. 2012. Universidade Federal de Pelotas.

Recebido em 28/11/2013

Aprovado em 01/08/2014 